\title{
Review
}

\section{Salvage Treatment for Progressive Brain Metastases in Breast Cancer}

\author{
Mateusz Jacek Spałek ${ }^{1, *(\mathbb{D})}$ and Tomasz Mandat ${ }^{2} \mathbb{D}$ \\ 1 Department of Soft Tissue/Bone Sarcoma and Melanoma, Maria Sklodowska-Curie National Research \\ Institute of Oncology, ul. W.K. Roentgena 5, 02-781 Warsaw, Poland \\ 2 Department of Neurosurgery, Maria Sklodowska-Curie National Research Institute of Oncology, ul. W.K. \\ Roentgena 5, 02-781 Warsaw, Poland; tomasz.mandat@pib-nio.pl \\ * Correspondence: mateusz.spalek@pib-nio.pl
}

check for

updates

Citation: Spałek, M.J.; Mandat, T. Salvage Treatment for Progressive Brain Metastases in Breast Cancer. Cancers 2022, 14, 1096. https:// doi.org/10.3390/cancers14041096

Academic Editor: David Brindley

Received: 6 December 2021

Accepted: 17 February 2022

Published: 21 February 2022

Publisher's Note: MDPI stays neutral with regard to jurisdictional claims in published maps and institutional affiliations.

Copyright: () 2022 by the authors Licensee MDPI, Basel, Switzerland. This article is an open access article distributed under the terms and conditions of the Creative Commons Attribution (CC BY) license (https:// creativecommons.org/licenses/by/ $4.0 /)$.
Simple Summary: Thirty percent of patients with human epidermal growth factor receptor 2-positive breast cancer and triple-negative breast cancer, and 15\% of patients with the remaining subtypes of breast cancer will develop brain metastases. Available treatment methods include surgery and radiotherapy. However, some individuals will experience intracranial progression despite prior local treatment. This situation remains a challenge. In the case of progressing lesions amenable to local therapy, the choice of a treatment method must consider performance status, cancer burden, possible toxicity, and previously applied therapy. Stereotactic radiosurgery or fractionated radiotherapy rather than whole-brain radiotherapy should be used only if feasible. If local therapy is unfeasible, selected patients, especially those with human epidermal growth factor receptor 2-positive breast cancer, may benefit from systemic therapy.

\begin{abstract}
Survival of patients with breast cancer has increased in recent years due to the improvement of systemic treatment options. Nevertheless, the occurrence of brain metastases is associated with a poor prognosis. Moreover, most drugs do not penetrate the central nervous system because of the blood-brain barrier. Thus, confirmed intracranial progression after local therapy is especially challenging. The available methods of salvage treatment include surgery, stereotactic radiosurgery (SRS), fractionated stereotactic radiotherapy (FSRT), whole-brain radiotherapy, and systemic therapies. This narrative review discusses possible strategies of salvage treatment for progressive brain metastases in breast cancer. It covers possibilities of repeated local treatment using the same method as applied previously, other methods of local therapy, and options of salvage systemic treatment. Repeated local therapy may provide a significant benefit in intracranial progression-free survival and overall survival. However, it could lead to significant toxicity. Thus, the choice of optimal methods should be carefully discussed within the multidisciplinary tumor board.
\end{abstract}

Keywords: breast cancer; brain metastases; intracranial progression; radiosurgery; stereotactic radiotherapy; whole-brain radiotherapy; reirradiation

\section{Introduction}

Breast cancer brain metastases (BCBM) represent the second most frequent secondary malignancy in the brain [1]. The introduction of modern systemic therapies has helped to prolong survival of patients with breast cancer. Thus, we observe the increasing incidence of BCBM that occur mostly in patients with human epidermal growth factor receptor 2 (HER2)-positive breast cancer and triple-negative breast cancer [2-5]. In a recent metaanalysis, it was found that the pooled cumulative incidence of BCBM was around 30\% for the HER2-positive subgroup and the triple-negative subgroup, and 15\% among patients with hormonal receptors positive HER2-negative breast cancer [6]. The diagnosis of BCBM 
is related to poor prognosis, neurological deficits, and impaired quality of life. Deterioration of the performance status may lead to discontinuation of thus far effective systemic treatment and close other treatment options, including clinical trials.

In the past, whole-brain radiotherapy (WBRT) was a gold standard of treatment for BCBM, but its efficacy is disputable [7]. The introduction of advanced surgical techniques and stereotactic radiotherapy, namely, single-fraction stereotactic radiosurgery (SRS) and fractionated stereotactic radiotherapy (FSRT), opened the possibilities of focused treatment without affecting the healthy brain, resulting in better local efficacy and a significant reduction of neurocognitive impairment associated with WBRT [8-10]. Contemporary radiotherapy techniques allow for treating multiple brain metastases at the same time without a decrease in efficacy [11]. Furthermore, selected patients with BCBM may survive several years using available modern treatment methods [12]. However, intracranial progression of previously treated BCBM remains a challenge due to lack of guidelines and risk of treatment-related toxicity. The most challenging situations comprise local progression after surgery or SRS/FSRT and disseminated intracranial progression after WBRT.

In this narrative review, we aimed to summarize data on treatment methods and research directions of salvage treatment for progressive BCBM. We hope that it will be useful in the clinical management of these patients and will help to identify the optimal treatment methods. All analyzed papers regarding methods of salvage treatment are summarized in Table S1.

\section{Definitions}

Progressive BCBM is defined as metastatic brain tumors from breast cancer that has been treated with any form of local therapy and recurred or progressed after it. A single patient may experience a progression of a solitary lesion or multiple metastases.

Local therapies for BCBM include neurosurgery, SRS, FSRT, and WBRT [13]. SRS is delivered in a single fraction of a dose on the basis of the maximum diameter of the tumor [14]. FSRT could be given in three, five, or more fractions and is usually applied in the case of larger lesions. Interestingly, the efficacy of both SRS and FSRT seems to be similar [15]. The summary of commonly prescribed doses is presented in Table 1.

Table 1. Fractionation regimens used in cranial radiosurgery and fractionated stereotactic radiotherapy.

\begin{tabular}{ccc}
\hline Type of Radiotherapy & Dose Range (Gy) & Indication \\
\hline \multirow{2}{*}{ SRS } & $20-24$ & max. tumor diameter $\leq 2.0 \mathrm{~cm}$ \\
& 18 & max. tumor diameter $2.1-3.0 \mathrm{~cm}$ \\
\multirow{2}{*}{ FSRT } & 15 & max. tumor diameter $3.1-4.0 \mathrm{~cm}$ \\
& $3 \times 7-9 \mathrm{~Gy}$ & tumors larger than $2 \mathrm{~cm}$ \\
\hline
\end{tabular}

FSRT—fractionated stereotactic radiotherapy; SRS—-stereotactic radiosurgery.

WBRT is usually delivered in $5(5 \times 4 \mathrm{~Gy})$ or $10(10 \times 3 \mathrm{~Gy})$ fractions. Longer regimens were found to be unfeasible due to lack of benefit in efficacy and increased frequency of adverse events [16].

\section{Diagnosis of Intracranial Progression}

The response of BM may be assessed using two systems: Response Evaluation Criteria in Solid Tumors (RECIST) and Response Assessment in Neuro-Oncology (RANO) criteria $[17,18]$. The advantage of RANO criteria is the inclusion of parameters associated with neurological status, the use of steroids, and the occurrence of pseudoprogression after SRS/FSRT or during immunotherapy. For example, the deterioration of neurological status is an independent criterion of intracranial progression, regardless of lack of increase in the target lesions diameters. RANO criteria are presented in Table 2. 
Table 2. Response Assessment in Neuro-Oncology criteria for brain metastases [17].

\begin{tabular}{|c|c|c|}
\hline Response & Number of Met Criteria & Criteria \\
\hline \multirow{5}{*}{ Complete response } & \multirow{5}{*}{ All } & No target lesions \\
\hline & & No non-target lesion \\
\hline & & No new lesions \\
\hline & & No deterioration of clinical status \\
\hline & & No steroids \\
\hline \multirow{5}{*}{ Partial response } & \multirow{5}{*}{ All } & $\geq 30 \%$ decrease in sum longest distance relative to baseline of target lesions \\
\hline & & At least stable non-target lesions \\
\hline & & No new lesions \\
\hline & & Stable or reduced steroids intake \\
\hline & & Stable or improved clinical status \\
\hline \multirow{5}{*}{ Stable disease } & \multirow{5}{*}{ All } & $\begin{array}{c}<30 \% \text { decrease relative to baseline but }<20 \% \text { increase in sum longest distance } \\
\text { relative to nadir of target lesions }\end{array}$ \\
\hline & & At least stable non-target lesions \\
\hline & & No new lesions \\
\hline & & Stable or reduced steroid intake \\
\hline & & Stable or improved clinical status \\
\hline \multirow{4}{*}{ Progressive disease } & \multirow{4}{*}{ Any } & $\geq 20 \%$ increase in sum longest distance relative to nadir of target lesion \\
\hline & & $\begin{array}{c}\text { unequivocal progression of existing enhancing or tumor-related } \\
\text { non-enhancing (T2/FLAIR) non-target lesions }\end{array}$ \\
\hline & & New lesions (except patients who receive immunotherapy) \\
\hline & & Deteriorated clinical status \\
\hline
\end{tabular}

According to the RANO criteria, the golden standard of monitoring of BM is gadoliniumenhanced T1 and T2 magnetic resonance imaging (MRI). Computed tomography should be only used exceptionally, for example, in the case of contraindications to MRI. Thin slice thickness is recommended, preferably less than $1.5 \mathrm{~mm}$. The lesion should have at least $1 \mathrm{~cm}$ in the longest diameter. That excludes lesions with unclear borders, meningeal infiltration, bone metastases, and purely cystic lesions. The maximum number of lesions should not exceed five. The brain is treated as a separate compartment and excluded from the extracranial assessment.

Special attention must be paid to the lesions that were irradiated with SRS or FSRT. Post-radiation necrosis (PRN) could mimic the progression of the BCBM $[19,20]$. This situation is relatively common; thus, the significance of the problem in a cohort of breast cancer patients with better prognosis and access to other treatment options is high due to the possibility of salvage treatment $[14,21,22]$. Several diagnostic modalities may help to differentiate between PRN and tumor progression. That includes MRI spectroscopy, positron emission tomography, single-photon emission computed tomography, and highresolution MRI with the assessment of perfusion and diffusion [23-29]. However, the only $100 \%$ reliable method of confirmation of progressive BCBM after SRS/FSRT is a pathological examination of the resected tumor. Nevertheless, its use may be limited by anatomical localization of the suspected lesion and postsurgical morbidity.

\section{Available Options of Local Salvage Treatment in Various Clinical Situations 4.1. Local Progression after WBRT}

In the case of limited local progression after WBRT, available treatment options include both salvage surgery and SRS/FSRT. Unfortunately, available literature on this topic consists only of retrospective data rather than clinical trials or prospective cohorts. 
The research group from Heidelberg (Germany) described the results of SRS for BCBM, including 39 patients who received salvage SRS after previous WBRT [30]. Median overall survival from the time of SRS reached an impressive 19 months. Younger age (<40 years) was the only factor associated with better outcomes.

Another group from the University of Texas M.D. Anderson Cancer Center reported outcomes from a similar cohort of patients who underwent WBRT for BCBM and salvage SRS due to the intracranial progression [31]. The median overall survival was 14 months. The one and two year overall survival of the 15 analyzed patients reached $55 \%$ and $23 \%$, respectively. One and two year local control rates in this group were $76 \%$ and $46 \%$, respectively. Higher Karnofsky performance score $(\geq 90)$, higher Score Index for Radiosurgery $(\geq 6)$, estrogen receptor positivity, and post-menopausal status were found to be associated with better survival.

Kased et al. published results of SRS for recurrent BCBM after previous WBRT $(n=81)$, surgery with WBRT $(n=18)$, and surgery alone $(n=4)$ [32]. The median overall survival was 11.7 months. Younger age ( $<50$ years), better performance status (Karnofsky performance score $\geq 70$ ), extracranial control, estrogen receptor positivity, and HER2 positivity were associated with longer survival. Importantly, the number of irradiated lesions did not affect survival time.

In another cohort analysis, the authors retrospectively assessed data of 79 patients with BCBM who underwent salvage SRS after previous therapy [33]. The group included 63 patients after WBRT, 13 patients after surgery and WBRT, 1 patient after total meningeal irradiation, 1 patient after surgery, and 1 patient after sole systemic therapy. The median intracranial progression-free survival after SRS was 5.7 months, whereas median overall survival reached 9.8 months. HER2 positivity and controlled extracranial disease were prognostic factors for survival.

Huang et al. assessed a cohort of 56 patients with BCBM who were reirradiated due to the intracranial progression [34]. In the first group, 39 patients underwent WBRT as an initial treatment and salvage SRS. The second group comprised 17 patients who initially received SRS and underwent salvage WBRT after intracranial progression. Patients who received salvage SRS had 6.5 months of median intracranial progression-free survival and 11.4 months of median overall survival. Results in the second group were similar, namely, 8.5 months of median intracranial progression-free survival and 10.8 months of median overall survival. The most important prognostic factor in both groups was performance status.

In another retrospective analysis, the authors assessed outcomes of 40 patients with BCBM who experienced intracranial progression after WBRT and received secondary radiotherapy [35]. A total of 12 patients received salvage SRS, 9 patients underwent FSRT, and 19 patients were irradiated with repeated WBRT. Median survival after salvage radiotherapy was low, but still significantly better in HER2-positive patients compared with HER2-negative patients (6 months vs. 2 months; $p=0.015)$.

\subsection{Local Progression after Local Treatment}

Intracranial local progression after surgery without postoperative radiotherapy may be limited to the surgical cavity or surroundings of the tumor bed. In both situations, salvage SRS and FSRT of progressive BCBM after surgical resection of the tumor should be used as a preferred method in patients with good performance status, only if feasible. Salvage WBRT should be reserved for patients with disseminated progression.

Intracranial local progression after SRS/FSRT may occur outside or within a previously irradiated volume. In the first situation, both surgery and repeated SRS/FSRT are considerable options [36]. The most challenging situations comprise local progression within the previously locally treated volume. Salvage surgery remains the mainstay method in the case of limited progression of BCBM after SRS or FSRT when progression occurs within previously irradiated lesions or is symptomatic. In the literature, there are no retrospective or prospective studies focused specifically on patients with resected progressive BCBM. 
Nevertheless, several studies investigating outcomes of surgical resection of progressive brain metastases from various cancers also covered patients with BCBM.

Kano et al. presented outcomes of 58 patients who underwent metastasectomy after SRS, including nine patients with breast cancer [37]. The survival rates in the entire cohort after surgery were 65,30 , and $16 \%$ at 6,12 , and 24 months, respectively. One patient with melanoma died due to intracranial hemorrhage, whereas four developed new neurological deficits.

Another study focused on results of surgical resection of suspected progression brain metastases after Gamma Knife SRS [38]. The group consisted of 32 patients from a cohort of 245 patients with brain metastases after Gamma Knife SRS. Among them, four patients had the diagnosis of BCBM. The 6, 12, and 24 month survival rates from the date of SRS of the whole cohort of patients who underwent Gamma Knife SRS were 70, 46, and 24\%, respectively. Interestingly, survival of the patients who previously underwent surgery $(97 \%$, 78 , and $47 \%$, respectively) was better than the survival of the patients without surgery $(65 \%, 40 \%$, and $19 \%$, respectively; $p<0.0001)$. Moreover, in four cases, postoperative specimens showed only PRN. The complication rate after surgery was relatively high. The neurological condition of four patients deteriorated, two patients developed systemic toxicity (deep venous thrombosis), and one died from malicious brain edema.

Nine patients with BCBM were analyzed within another cohort of patients who underwent resection of progressive brain metastases after SRS [39]. The authors used a risk-adapted approach. They divided lesions into those localized in non-eloquent and eloquent brain regions. Those localized in the non-eloquent regions were resected radically by using a fence-post method. Lesions localized in the eloquent areas were removed using the piecemeal technique without margins, followed by postoperative SRT. No significant differences in local recurrence rate between the fore mentioned subgroups were found (34.6\% in minimum resection \pm SRS group vs. $14.3 \%$ in wide resection group, $p=0.07$ ). The median overall survival after salvage surgery reached 20.2 months. What is particularly important is that primary breast cancer was found to be a good prognostic factor for overall survival (breast vs. lung: hazard ratio 0.17 ; breast vs. others: hazard ratio 0.08 ). The authors did not report any significant toxicity after surgery. This study also suggested that postoperative radiotherapy after resection of progressive previously irradiated BCBM may be justified. Unfortunately, no prospective trials on this topic exist.

Repeated SRS is associated with a higher risk of PRN. It is highly advisable to make an image registration and assess a composite dose (see Figure 1).

In a study published by McKay et al., 32 patients, including 9 with BCBM, received reSRS to 46 progressive lesions [40]. After one year follow-up, survival was 70\%. The authors identified nine events of local progression that translated into $79 \%$ of one year local control for each lesion and 95.6 months of median time to local failure after re-SRS. Nevertheless, only $44 \%$ of local progression occurred within the irradiated volume. The toxicity of re-SRS was significant. In $30 \%$ of the patients, PRN was identified. In $24 \%$ of patients, PRN was symptomatic. That included dyscoordination, motor weakness, vision impairment, aphasia, and hemorrhage. Freedom from PRN at 1 year was $71 \%$. The $10 \%, 20 \%$, and $50 \%$ probabilities of PRN were associated with irradiated volumes receiving $40 \mathrm{~Gy}$ or higher at $0.28 \mathrm{~cm}^{3}, 0.76 \mathrm{~cm}^{3}$, and $1.6 \mathrm{~cm}^{3}$, respectively.

The authors of another study on re-SRS and SRT evaluated 28 patients with 32 brain metastases who received such a treatment [41]. The cohort included five patients with BCBM. The median overall survival was 22 months. The local control rate after re-SRS was $84.4 \%$. The one and two year local control rates were $88.3 \%$ and $80.3 \%$, respectively. PRN was found in $18.8 \%$ of lesions. Higher prescribed isodose line $(p=0.033)$ and higher gross tumor volume $(p=0.015)$ were predictive factors for PRN in a univariate analysis. 

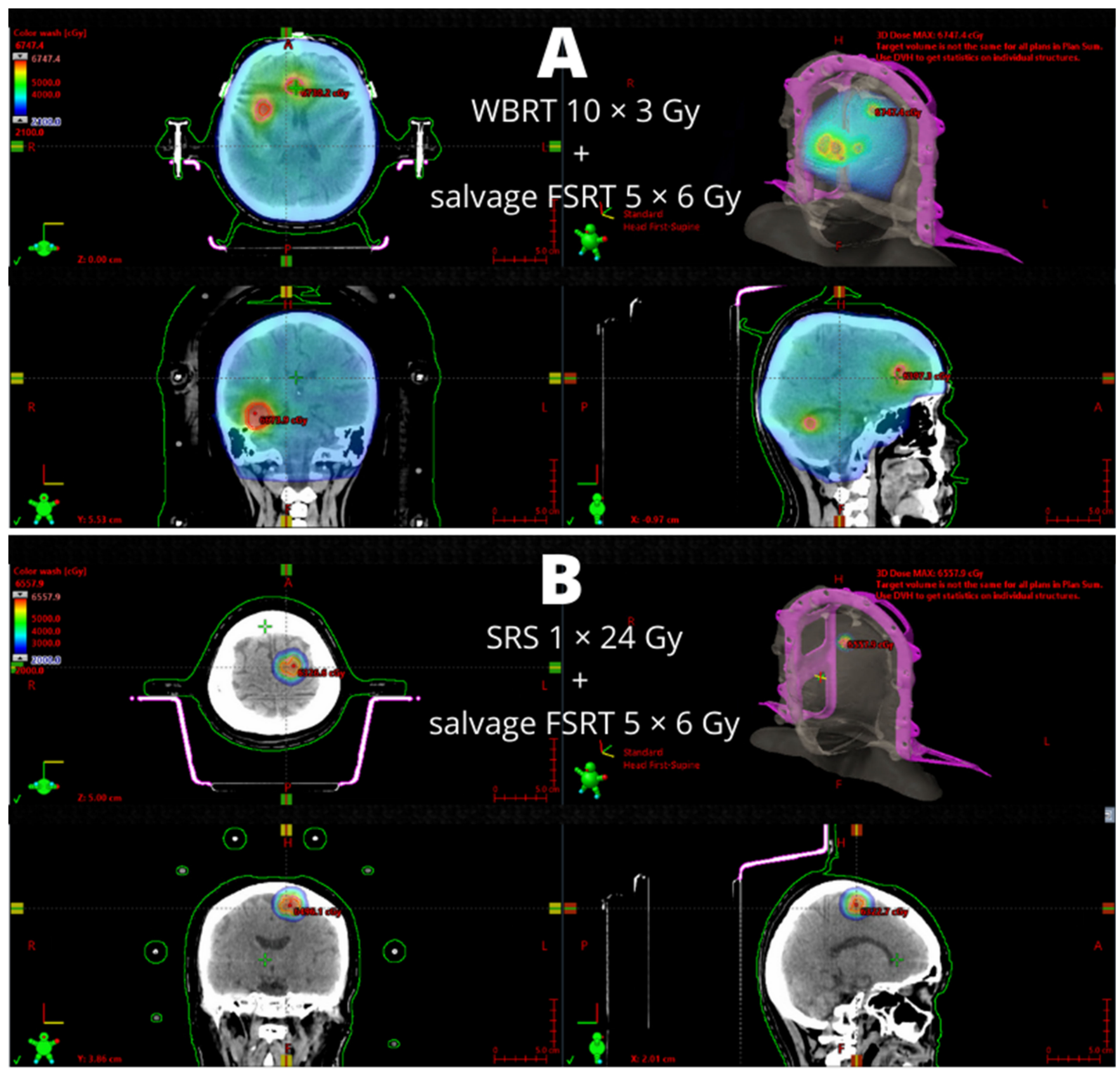

FSRT - fractionated stereotactic radiotherapy; SRS - stereotactic radiosurgery

Figure 1. Reirradiation due to limited intracranial progression. (A) Salvage fractionated stereotactic radiotherapy $(5 \times 6 \mathrm{~Gy})$ for five progressive brain metastases after whole-brain radiotherapy $(10 \times 3$ Gy). (B) Repeated fractionated stereotactic radiotherapy $(5 \times 6 \mathrm{~Gy})$ for one progressive brain lesion after prior stereotactic radiosurgery $(1 \times 24 \mathrm{~Gy})$ in a patient who refused salvage surgery.

Interesting results were provided by the authors of systematic review and metaanalysis on efficacy and safety of re-SRS or re-FSRT for brain metastases [42]. After a literature search according to PRISMA guidelines, 13 studies with 464 patients and 549 brain metastases were included. One year local control was from $46.5 \%$ to $88.3 \%$. Pathological diagnosis of melanoma, no prior WBRT, larger tumor volume, lower given dose, inadequate response after primary SRS, poorer performance status, and uncontrolled extracranial disease were predictive for worse local control. The authors reported a crude median value of PRN as 14.3\% (from 2\% to 36\%). Moreover, three studies included in the review 
described significant risk factors for PRN. This included larger irradiated tumor volume, higher given dose, the large overlap between previously and currently irradiated volumes at doses of 18 and $12 \mathrm{~Gy}$, and a higher covering isodose.

\subsection{Disseminated Intracranial Progression}

Disseminated intracranial progression may occur after local treatment or WBRT. In the first situation, available salvage treatment options include WBRT and, in selected situations, local treatment. WBRT remains the method of choice in the case of numerous progressive BCBM, especially for patients with HER-2-positive and hormone receptor-positive breast cancer. However, contemporary radiotherapy techniques allow for simultaneous or sequential focal treatment of multiple progressive BCBM without loss in local efficacy $[11,43,44]$. Thus, even a progression of more than four BCBM is not a default indication for WBRT or best supportive care only. The choice of treatment method should rather be based on patient performance status, availability of systemic treatment options, radiotherapy equipment, the total volume of progressing tumors, and dosimetric parameters $[45,46]$. FSRT may be preferred over SRT if there is a significant risk of PRN [15].

In multiple BCBM, surgery can be combined with SRS/FSRT or WBRT, especially if there is a dominant lesion that causes significant edema, bleeding, or neurological symptoms $[47,48]$. After resection of the dominant metastatic tumor, the remaining lesions could be irradiated with or without a postsurgical bed using stereotactic methods or WBRT. However, data regarding the efficacy and tolerability of such an approach is scarce.

In the case of progression of numerous BCBM after prior WBRT, the available options of salvage treatment include repeated WBRT and systemic therapy with intracranial activity. Repeated WBRT could be offered to carefully selected patients with disseminated BCBM. The most commonly used regimens are usually more conservative than in primary WBRT, i.e., $20 \mathrm{~Gy}$ in 10 fractions. The tolerability of such an approach seems to be acceptable; however, the survival of patients after re-WBRT is usually poor, and data regarding late toxicity do not exist. Guo et al. reported outcomes of 41 patients treated with secondary WBRT [49]. The cohort included eight patients with BCBM. The median overall survival following re-WBRT was 3.3 months.

\subsection{Leptomeningeal Disease}

Development of leptomeningeal disease is relatively rare but is a serious event associated with poor prognosis in patients with breast cancer [50]. It is defined as the infiltration of the leptomeninges by cancer cells and their presence in the cerebrospinal fluid. It may be confirmed in MRI or cerebrospinal fluid analysis. There are no studies that directly focus on salvage treatment of secondary leptomeningeal disease after prior treatment for BCMC.

In the case of primary leptomeningeal disease, the method of choice is WBRT. However, the real benefit of such a treatment is disputable, and the prognosis remains very poor. Twenty-two patients with breast cancer and leptomeningeal metastases who underwent WBRT presented poor median overall survival [51]. Patients in good performance status and absence of solitary BCBM gained the most from WBRT. Similar poor results regarding survival after WBRT for leptomeningeal BCBM were reported by Gani et al. [52].

Leptomeningeal disease most commonly presents diffuse character. Thus, SRS and FSRT are not the methods of choice. However, in a small retrospective study, the authors analyzed a cohort of 16 patients, including 5 patients with BCBM who underwent SRT for focal leptomeningeal metastases [53]. It resulted in 10 months of median overall survival in the entire group. Six patients received salvage WBRT due to the intracranial progression. Thus, SRT and FSRT may be applied to carefully selected patients with limited localized leptomeningeal metastases who are in good performance status and are potential candidates for further systemic therapy. 


\subsection{Subtype-Tailored Treatment}

In the case of multiple but countable BCBM, the choice between WBRT and SRS/FSRT remains unsolved. The use of local treatment without WBRT is associated with the higher risk of intracranial failure outside the irradiated volume. On the other hand, WBRT is related to the higher risk of neurocognitive disfunction [9]. Moreover, there is no difference in overall survival between patients who received WBRT and those who underwent SRS, regardless the higher risk of intracranial failure. SRS may be safely used, even in the case of multiple brain metastases [54,55]. Thus, repeated SRS/FSRT seems to be also a valid treatment strategy.

Breast cancer subtype may be a prognostic marker for survival following treatment for BCBM. Patients with HER-positive and triple-negative breast cancer have the poorest survival after brain radiotherapy [56]. However, in HER-2 positive BCBM, survival increases after addition of HER-2-targeted therapy to irradiation [5]. Unfortunately, there are no data on the rate of intracranial failure following SRS for each breast cancer subtype. A valuable tool to assess expected survival of patients with BCBM is the most recent version of graded prognostic assessment (GPA) [57]. It covers not only the performance status but also breast cancer subtype, age, number of BCBM, and the presence of extracranial metastases. All these factors should be considered when choosing a salvage treatment.

\section{Salvage Systemic Therapy}

The efficacy of systemic agents in the brain is limited by the blood-brain barrier (BBB) [58]. However, selected systemic therapies showed activity against BCBM [59]. If the intracranial progression occurs during a systemic treatment and there are no options of local therapy, it is reasonable to switch systemic therapy lines. Nevertheless, there are no prospective clinical trials with systemic treatment focused on patients with BCBM that progressed after local therapy. Limited data exist in the form of retrospective studies and subgroup analyses from prospective trials on patients with brain metastases.

\subsection{All Breast Cancer Subtypes}

Although many commonly used systemic agents in breast cancer do not cross the $\mathrm{BBB}$, some of them present intracranial activity due to impaired vessel permeability caused by brain metastases. In a prospective nonrandomized study published by Boogerd et al., 22 patients with BCBM received either cyclophosphamide, methotrexate, and 5-fluorouracil (20 patients) or cyclophosphamide, doxorubicin, and 5-fluorouracil (two patients) chemo regimens [60]. The cohort included seven patients who had been previously locally treated for BCBM. The authors observed a significant clinical benefit in 5/7 abovementioned patients and signs of radiological response in $4 / 7$ patients. The achieved response lasted more than 20 weeks in four of them.

Temozolomide is an alkylating agent that significantly penetrates the BBB. It is widely used in the treatment of primary and secondary brain gliomas. However, it has been also investigated in the treatment of brain metastases [61]. Results of the Hellenic Cooperative Oncology Group phase II clinical trial suggested relatively high intracranial activity of temozolomide in patients with brain metastases from solid tumors [62]. Among them, almost $50 \%$ had a diagnosis of breast cancer. The primary endpoint of this study was the response to investigated chemo regimen both in intracranial and extracranial disease. The previously treated patients received temozolomide $150 \mathrm{mg} / \mathrm{m}^{2}$, whereas chemotherapy-naïve patients were treated with temozolomide $200 \mathrm{mg} / \mathrm{m}^{2}$ for 5 days. Temozolomide was given concurrently with cisplatin $75 \mathrm{mg} / \mathrm{m}^{2}$. The cycles were repeated every 28 days. Among 15 patients with BCBM, partial response was observed in 6 of them. In the manuscript, the number of patients with BCBM who experienced stable disease or progressive disease was not stated. The treatment was well-tolerated; however, one toxic death of a breast cancer patient with hepatic and brain metastases was reported. Temozolomide was also investigated in combination with capecitabine in a prospective phase I clinical trial dedicated to patients with BCBM [63]. The primary endpoint of the study was the assessment 
of the maximum tolerated dose of the combination of temozolomide and capecitabine in patients with BCBM. The patients were divided into four cohorts who received investigated medications at different dosing levels on days 1-5 and days 8-12, with cycles repeated every 21 days. A total of 24 patients were enrolled, including 10 patients with progressive BCBM. The authors reported one complete and three partial responses. Half of the patients experienced stable disease. Importantly, partial responses were observed in two patients who previously underwent WBRT. The median duration of the response was eight weeks. Toxicity was typical to the investigated regimen and resulted in dose reduction among two cases. In another phase II clinical trial on patients with progressive brain metastases the from various origin, temozolomide $\left(150 \mathrm{mg} / \mathrm{m}^{2}\right.$ for patients who received any prior chemotherapy and $200 \mathrm{mg} / \mathrm{m}^{2}$ for chemotherapy-naïve patients) was given as a single agent. Among 41 patients, 10 had BCBM. Among four patients with BCBM, the disease was stabilized; in the other three, the progression of the disease was observed; and the remaining three patients were not eligible for analysis. The treatment was well tolerated. In summary, temozolomide seems to be an interesting option for patients with progressive BCBC. However, it is currently almost exclusively used in the treatment of malignant glioma.

Another agent is bevacizumab, a recombinant humanized monoclonal antibody against vascular endothelial growth factor. It inhibits angiogenesis, decreases the rate of contrast-enhancing lesions, reduces brain edema, and allows for the reduction in or withdrawing of steroids [64]. In a retrospective study performed at the University of Heidelberg (Germany) and the Medical University of Vienna (Austria), the authors assessed the efficacy of bevacizumab, a monoclonal antibody against vascular endothelial growth factor, as salvage therapy in patients with symptomatic, recurrent brain metastases who were not candidates for any form of local therapy [65]. The study group consisted of 22 patients, including 9 patients with BCBM. All of them were previously irradiated (WBRT or SRS), and two of them underwent brain metastasectomy. The median length of bevacizumab therapy was five months. The most frequent reason for treatment withdrawal was the progression of the disease. Neurological improvement was observed in most treated patients $(64 \%)$, whereas stabilization was found in $27 \%$. Thus, the clinical benefit occurred in $91 \%$ of patients who received bevacizumab.

\subsection{Triple-Negative Breast Cancer}

The options of systemic treatment of patients with triple-negative BCBM are limited to conventional chemotherapy. Nevertheless, several drugs are investigated in this particularly challenging breast cancer subtype. Sacituzumab govitecan combines a humanized antibody against tumor-associated calcium signal transducer with the active metabolite of irinotecan. It is approved for the treatment of patients with metastatic triple-negative breast cancer [66]. The early results of a clinical trial NCT03995706 showed an intracranial activity of sacituzumab govitecan in patients with BCBM and recurrent glioblastoma [67].

Another investigated combination against triple-negative BCBM comprised iniparib and irinotecan [68]. Thirty-seven patients were enrolled. Thirty-four were eligible for evaluation. The median time to progression was 2 months. The median overall survival reached 8 months. Objective response to the treatment was observed in $12 \%$ of patients, whereas the clinical benefit rate was $27 \%$. The toxicity of investigated regimen was acceptable.

An interesting concept of innovative drug delivery through the BBB was described by Zhang et al. [69]. The authors invented a terpolymer-lipid hybrid nanoparticle system for the treatment of integrin-overexpressing triple-negative BCBM. It was loaded with doxorubicin and mitomycin $C$. The system significantly reduced metastatic burden and increased host survival in in vitro and in vivo studies; however, it requires further development and clinical trials. 


\subsection{HER2-Positive Breast Cancer}

HER2 tyrosine kinase inhibitors present intracranial activity in patients with HER2positive BCBM. In the exploratory analysis of the HER2CLIMB clinical trial, the authors reported outcomes regarding intracranial efficacy and survival of patients with HER2positive $\mathrm{BCBM}$ who received tucatinib or placebo, in combination with trastuzumab and capecitabine [70]. Among 291 patients enrolled in this trial, 108 had progressive BCBM. Patients with active BCBM, defined as progressive or untreated lesions, estimated that one year central nervous system progression-free survival was $35 \%$ in those who received tucatinib and $0 \%$ in patients who received placebo. This resulted in a $64 \%$ reduced risk of intracranial progression or death in the tucatinib arm compared to the placebo arm (hazard ratio $0.36, p<0.0001$ ) and translated into better overall survival in the subgroup who received tucatinib (20.7 months) versus placebo (11.6 months). Moreover, patients with HER2-positive BCBM who were treated with tucatinib showed more intracranial overall responses $(47.3 \%)$ than those who took a placebo $(20 \%, p=0.03)$.

Lapatinib alone showed modest intracranial activity in a large phase II clinical trial that exclusively enrolled 242 patients with progressive HER2-positive BCBM who were previously treated with trastuzumab and radiotherapy [71]. Objective intracranial responses and a $\geq 20 \%$ volumetric reduction of brain lesions were noted in $6 \%$ and $21 \%$ of patients, respectively. The amendment allowed patients who progressed on lapatinib to receive lapatinib with capecitabine. Among 50 patients eligible for analysis, objective intracranial responses and $\geq 20 \%$ volumetric reductions of brain lesions were observed in $20 \%$ and $40 \%$, respectively. Another phase I study with high dose lapatinib alternating with capecitabine also showed intracranial activity of such a combination [72].

Another HER2 tyrosine kinase inhibitor, neratinib, was investigated in combination with capecitabine in patients with progressive HER2-positive BCBM [73]. The patients were enrolled into two cohorts, namely, those who received previous treatment with lapatinib (cohort 3B) and lapatinib-naïve patients (cohort 3A). The primary endpoint of the study was the intracranial objective response rate calculated separately in each cohort. Objective response was defined as a reduction of $50 \%$ or more in the sum of target BCBM volumes without progression of nontarget lesions, new lesions, escalating steroids, progressive neurologic signs or symptoms, or extracranial progression. Cohort $3 \mathrm{~A}$ enrolled 37 patients. Twelve patients entered cohort 3B. Intracranial objective response rates in cohort $3 \mathrm{~A}$ and 3B were $49 \%$ and $33 \%$, respectively. Median progression-free survival and overall survival reached 5.5 and 13.3 months in cohort $3 \mathrm{~A}$, respectively. Corresponding values for cohort $3 \mathrm{~B}$ were 3.1 and 15.1 months, respectively. The most common grade 3 adverse event was diarrhea ( $29 \%$ in each cohort).

Trastuzumab emtansine presented a significant intracranial activity. In a single-arm phase IIIb clinical trial KAMILLA, response to the drug was observed in both previously irradiated and non-irradiated brain lesions [74]. However, the investigated drug was given to the patients with stable BCBM. Even better results were found in the recently published subgroup analysis from a phase III DESTINY-Breast03 trial. Patients with HER2-positive BCBM who received fam-trastuzumab deruxtecan-nxki (T-DXd) had significantly better intracranial response (intracranial response rate $63.8 \%$ ) and 12 month progression-free survival $(72 \%)$ in comparison with patients who were treated with trastuzumab emtansine (intracranial response rate of 33.3\%, 12 month progression-free survival of 20.9\%) [75]. Moreover, the group who received T-DXd had 75\% lower relative risk of progression or death than patients from the trastuzumab emtansine group. Another salvage systemic treatment strategy could be the use of pertuzumab combined with high-dose trastuzumab [76] Among 39 patients with progressive BCBM, such a treatment allowed for $11 \%$ of the intracranial overall response rate. Sixty-eight percent of patients experienced clinical benefit from the treatment, including two patients who had stable intracranial and extracranial disease for more than two years. 


\subsection{Hormone Receptor-Positive Breast Cancer}

Few case series and case reports have shown the intracranial response of hormone receptor-positive BCBM [77-79]. However, no clinical trials or large retrospective studies have evaluated the efficacy of hormonal therapy as a salvage treatment for progressive BCBM. Thus, such a therapy should not be considered in this clinical situation. Cyclindependent kinase $4 / 6$ inhibitors showed a moderate intracranial response in early phase clinical trials in patients with hormone receptor-positive BCBM [80,81].

\section{Summary and Conclusions}

Contemporary methods of local treatment for progressing BCBM provide good local efficacy and acceptable toxicity. The evolution of radiotherapy techniques allows for repeating focal treatment of multiple brain metastases. SRS or FSRT can be combined with surgery to increase intracranial control of the disease. SRS or FSRT can be repeated for previously irradiated volumes; however, this brings about a significant risk of PRN. Repeated WBRT could be offered to carefully selected patients with intracranial progression of numerous BCBM that are not amenable to SRS or FSRT. The benefit of WBRT is disputable. Systemic treatment may be an alternative option if local therapy is not feasible. The proposed methods of salvage treatment are summarized in Figure 2.

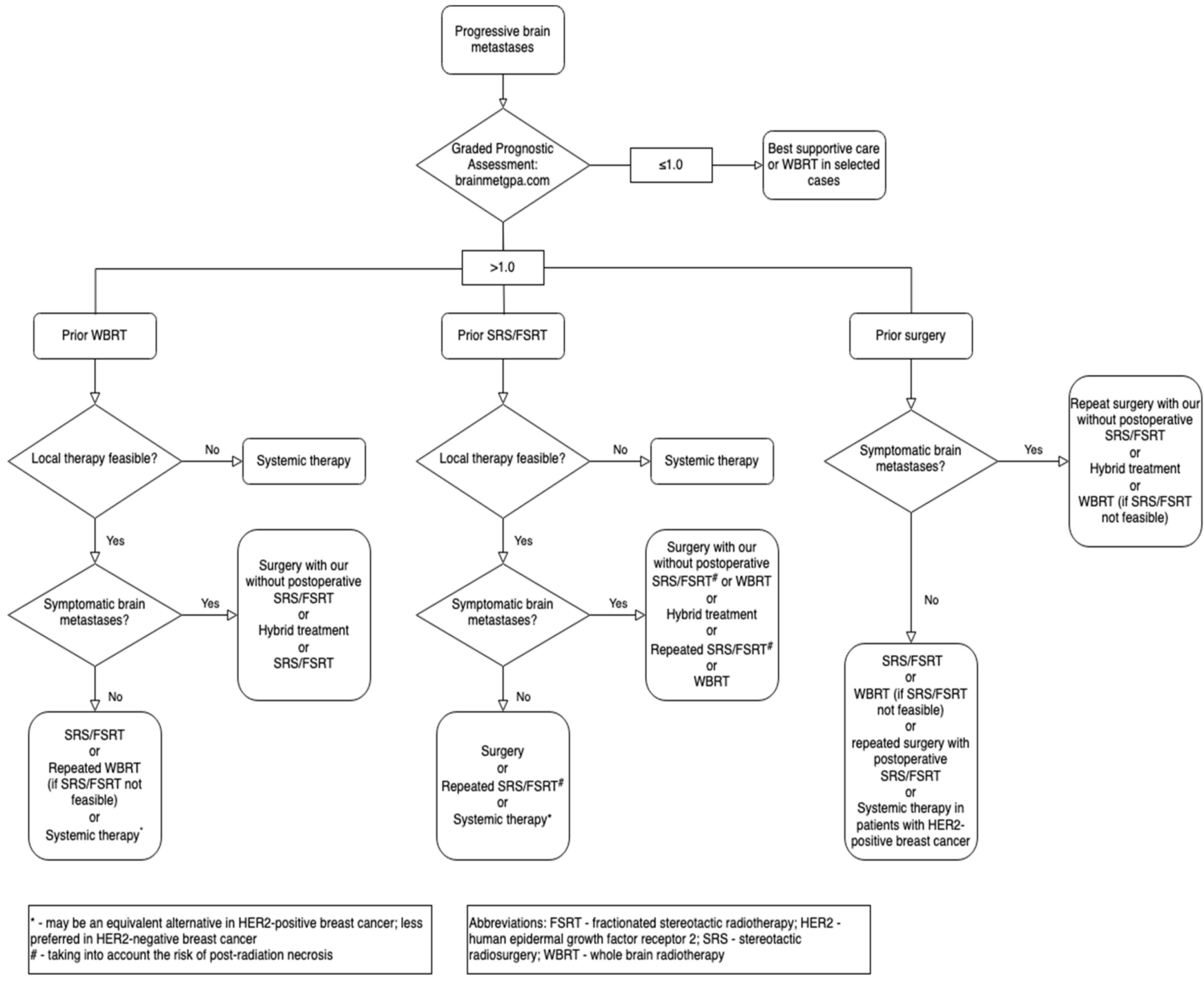

Figure 2. Salvage treatment methods for progressive brain metastases in breast cancer after prior local therapy. 
Nevertheless, the overall results of the salvage treatment of patients with progressive $\mathrm{BCBM}$ remain poor, mostly due to the progression outside treated lesions. There is a growing role of systemic treatment of progressing BCBM, including immunotherapy, targeted therapies, and special techniques of drug delivery. Patients with HER2-positive breast cancer have the widest scope of possible treatments that are effective, especially combinations of HER2 tyrosine kinase inhibitors with capecitabine and other agents. Systemic therapies may be combined with other available methods of local treatment to maximize survival. The selection of methods depends on performance status, disease burden, comorbidities, a biological subtype of breast cancer, and previously used therapies. The treatment decisions should be made at the multidisciplinary tumor board meetings that include at least neurosurgeon, radiation oncologist, and medical oncologist [82-84].

Supplementary Materials: The following supporting information can be downloaded at: https: //www.mdpi.com/article/10.3390/cancers14041096/s1. Table S1: Methods of salvage treatment in breast cancer brain metastases-analysis of available data and the quality of evidence.

Author Contributions: Conceptualization, M.J.S.; methodology, M.J.S.; software, M.J.S.; validation, T.M.; formal analysis, M.J.S.; investigation, M.J.S.; resources, M.J.S.; data curation, M.J.S.; writing—original draft preparation, M.J.S.; writing—review and editing, M.J.S. and T.M.; visualization, M.J.S.; supervision, T.M.; project administration, M.J.S.; funding acquisition, M.J.S. All authors have read and agreed to the published version of the manuscript.

Funding: This review received no external funding. The processing charges cost was covered by the Maria Sklodowska-Curie National Research Institute of Oncology, Warsaw, Poland.

Conflicts of Interest: The authors declare no conflict of interest related to this manuscript.

\section{References}

1. Lin, N.U.; Bellon, J.R.; Winer, E.P. CNS Metastases in Breast Cancer. J. Clin. Oncol. 2004, 22, 3608-3617. [CrossRef] [PubMed]

2. Gabos, Z.; Sinha, R.; Hanson, J.; Chauhan, N.; Hugh, J.; Mackey, J.R.; Abdulkarim, B. Prognostic Significance of Human Epidermal Growth Factor Receptor Positivity for the Development of Brain Metastasis After Newly Diagnosed Breast Cancer. J. Clin. Oncol. 2006, 24, 5658-5663. [CrossRef] [PubMed]

3. Tham, Y.-L.; Sexton, K.; Kramer, R.; Hilsenbeck, S.; Elledge, R. Primary breast cancer phenotypes associated with propensity for central nervous system metastases. Cancer 2006, 107, 696-704. [CrossRef] [PubMed]

4. Pestalozzi, B.C.; Zahrieh, D.; Price, K.N.; Holmberg, S.B.; Lindtner, J.; Collins, J.; Crivellari, D.; Fey, M.F.; Murray, E.; Pagani, O.; et al. Identifying breast cancer patients at risk for Central Nervous System (CNS) metastases in trials of the International Breast Cancer Study Group (IBCSG). Ann. Oncol. 2006, 17, 935-944. [CrossRef]

5. Nam, B.-H.; Kim, S.Y.; Han, H.-S.; Kwon, Y.; Lee, K.S.; Kim, T.H.; Ro, J. Breast cancer subtypes and survival in patients with brain metastases. Breast Cancer Res. 2008, 10, R20. [CrossRef]

6. Kuksis, M.; Gao, Y.; Tran, W.; Hoey, C.; Kiss, A.; Komorowski, A.S.; Dhaliwal, A.J.; Sahgal, A.; Das, S.; Chan, K.K.; et al. The incidence of brain metastases among patients with metastatic breast cancer: A systematic review and meta-analysis. Neuro-Oncology 2020, 23, 894-904. [CrossRef]

7. Frisk, G.; Tinge, B.; Ekberg, S.; Eloranta, S.; Bäcklund, L.M.; Lidbrink, E.; Smedby, K.E. Survival and level of care among breast cancer patients with brain metastases treated with whole brain radiotherapy. Breast Cancer Res. Treat. 2017, 166, 887-896. [CrossRef]

8. Tallet, A.V.; Azria, D.; Barlesi, F.; Spano, J.-P.; Carpentier, A.F.; Gonçalves, A.; Metellus, P. Neurocognitive function impairment after whole brain radiotherapy for brain metastases: Actual assessment. Radiat. Oncol. 2012, 7, 77. [CrossRef]

9. Chang, E.L.; Wefel, J.S.; Hess, K.R.; Allen, P.K.; Lang, F.F.; Kornguth, D.G.; Arbuckle, R.B.; Swint, J.M.; Shiu, A.S.; Maor, M.H.; et al. Neurocognition in patients with brain metastases treated with radiosurgery or radiosurgery plus whole-brain irradiation: A randomised controlled trial. Lancet Oncol. 2009, 10, 1037-1044. [CrossRef]

10. Halasz, L.M.; Uno, H.; Hughes, M.; D’Amico, T.; Dexter, E.U.; Edge, S.B.; Hayman, J.A.; Niland, J.C.; Otterson, G.A.; Pisters, K.M.W.; et al. Comparative effectiveness of stereotactic radiosurgery versus whole-brain radiation therapy for patients with brain metastases from breast or non-small cell lung cancer. Cancer 2016, 122, 2091-2100. [CrossRef]

11. Kraft, J.; van Timmeren, J.E.; Mayinger, M.; Frei, S.; Borsky, K.; Stark, L.S.; Krayenbuehl, J.; Zamburlini, M.; Guckenberger, M.; Tanadini-Lang, S.; et al. Distance to isocenter is not associated with an increased risk for local failure in LINAC-based single-isocenter SRS or SRT for multiple brain metastases. Radiother. Oncol. 2021, 159, 168-175. [CrossRef]

12. Lin, N.U.; Amiri-Kordestani, L.; Palmieri, D.; Liewehr, D.J.; Steeg, P.S. CNS Metastases in Breast Cancer: Old Challenge, New Frontiers. Clin. Cancer Res. 2013, 19, 6404-6418. [CrossRef]

13. Lin, X.; DeAngelis, L.M. Treatment of Brain Metastases. J. Clin. Oncol. 2015, 33, 3475-3484. [CrossRef] 
14. Shaw, E.; Scott, C.; Souhami, L.; Dinapoli, R.; Kline, R.; Loeffler, J.; Farnan, N. Single dose radiosurgical treatment of recurrent previously irradiated primary brain tumors and brain metastases: Final report of RTOG protocol 90-05. Int. J. Radiat. Oncol. 2000, 47, 291-298. [CrossRef]

15. Lehrer, E.J.; Peterson, J.L.; Zaorsky, N.G.; Brown, P.D.; Sahgal, A.; Chiang, V.L.; Chao, S.T.; Sheehan, J.P.; Trifiletti, D.M. Single versus Multifraction Stereotactic Radiosurgery for Large Brain Metastases: An International Meta-analysis of 24 Trials. Int. J. Radiat. Oncol. 2018, 103, 618-630. [CrossRef]

16. Trifiletti, D.M.; Ballman, K.V.; Brown, P.D.; Anderson, S.K.; Carrero, X.W.; Cerhan, J.H.; Whitton, A.C.; Greenspoon, J.; Parney, I.F.; Laack, N.N.; et al. Optimizing Whole Brain Radiation Therapy Dose and Fractionation: Results From a Prospective Phase 3 Trial (NCCTG N107C [Alliance]/CEC.3). Int. J. Radiat. Oncol. 2019, 106, 255-260. [CrossRef]

17. Lin, N.U.; Lee, E.Q.; Aoyama, H.; Barani, I.J.; Barboriak, D.P.; Baumert, B.G.; Bendszus, M.; Brown, P.D.; Camidge, D.R.; Chang, S.M.; et al. Response assessment criteria for brain metastases: Proposal from the RANO group. Lancet Oncol. 2015, 16, e270-e278. [CrossRef]

18. Schwartz, L.H.; Litière, S.; de Vries, E.; Ford, R.; Gwyther, S.; Mandrekar, S.; Shankar, L.; Bogaerts, J.; Chen, A.; Dancey, J.; et al. RECIST 1.1-Update and clarification: From the RECIST committee. Eur. J. Cancer 2016, 62, 132-137. [CrossRef]

19. Peterson, A.M.; Meltzer, C.C.; Evanson, E.J.; Flickinger, J.C.; Kondziolka, D. MR Imaging Response of Brain Metastases after Gamma Knife Stereotactic Radiosurgery. Radiology 1999, 211, 807-814. [CrossRef]

20. E Huber, P.; Hawighorst, H.; Fuss, M.; van Kaick, G.; Wannenmacher, M.F.; Debus, J. Transient enlargement of contrast uptake on MRI after linear accelerator (linac) stereotactic radiosurgery for brain metastases. Int. J. Radiat. Oncol. 2001, 49, 1339-1349. [CrossRef]

21. Ross, D.A.; Sandler, H.M.; Balter, J.M.; Hayman, J.A.; Archer, P.G.; Auer, D.L. Imaging changes after stereotactic radiosurgery of primary and secondary malignant brain tumors. J. Neuro-Oncology 2002, 56, 175-181. [CrossRef]

22. Varlotto, J.M.; Flickinger, J.; Niranjan, A.; Bhatnagar, A.K.; Kondziolka, D.; Lunsford, L. Analysis of tumor control and toxicity in patients who have survived at least one year after radiosurgery for brain metastases. Int. J. Radiat. Oncol. 2003, 57, 452-464. [CrossRef]

23. Nichelli, L.; Casagranda, S. Current emerging MRI tools for radionecrosis and pseudoprogression diagnosis. Curr. Opin. Oncol. 2021, 33, 597-607. [CrossRef]

24. Liu, Z.-C.; Yan, L.-F.; Hu, Y.-C.; Sun, Y.-Z.; Tian, Q.; Nan, H.-Y.; Yu, Y.; Sun, Q.; Wang, W.; Cui, G.-B. Combination of IVIMDWI and 3D-ASL for differentiating true progression from pseudoprogression of Glioblastoma multiforme after concurrent chemoradiotherapy: Study protocol of a prospective diagnostic trial. BMC Med Imaging 2017, 17, 10. [CrossRef]

25. Chao, S.T.; Suh, J.H.; Raja, S.; Lee, S.-Y.; Barnett, G. The sensitivity and specificity of FDG PET in distinguishing recurrent brain tumor from radionecrosis in patients treated with stereotactic radiosurgery. Int. J. Cancer 2001, 96, 191-197. [CrossRef]

26. Henry, R.G.; Vigneron, D.B.; Fischbein, N.J.; Grant, P.E.; Day, M.R.; Noworolski, S.M.; Star-Lack, J.M.; Wald, L.L.; Dillon, W.P.; Chang, S.M.; et al. Comparison of Relative Cerebral Blood Volume and Proton Spectroscopy in Patients with Treated Gliomas. Am. J. Neuroradiol. 2000, 21, 357-366.

27. Serizawa, T.; Saeki, N.; Higuchi, Y.; Ono, J.; Matsuda, S.; Sato, M.; Yanagisawa, M.; Iuchi, T.; Nagano, O.; Yamaura, A. Diagnostic value of thallium-201 chloride single-photon emission computerized tomography in differentiating tumor recurrence from radiation injury after gamma knife surgery for metastatic brain tumors. J. Neurosurg. 2005, 102, 266-271. [CrossRef]

28. Sugahara, T.; Korogi, Y.; Tomiguchi, S.; Shigematsu, Y.; Ikushima, I.; Kira, T.; Liang, L.; Ushio, Y.; Takahashi, M. Posttherapeutic Intraaxial Brain Tumor: The Value of Perfusion-sensitive Contrast-enhanced MR Imaging for Differentiating Tumor Recurrence from Nonneoplastic Contrast-enhancing Tissue. Am. J. Neuroradiol. 2000, 21, 901-909.

29. Hoefnagels, F.W.A.; Lagerwaard, F.J.; Sanchez, E.; Haasbeek, C.J.A.; Knol, D.L.; Slotman, B.J.; Vandertop, W.P. Radiological progression of cerebral metastases after radiosurgery: Assessment of perfusion MRI for differentiating between necrosis and recurrence. J. Neurol. 2009, 256, 878-887. [CrossRef]

30. Combs, S.E.; Schulz-Ertner, D.; Thilmann, C.; Edler, L.; Debus, J. Treatment of Cerebral Metastases from Breast Cancer with Stereotactic Radiosurgery. Strahlenther. und Onkol. 2004, 180, 590-596. [CrossRef]

31. Akyurek, S.; Chang, E.L.; Mahajan, A.; Hassenbusch, S.J.; Allen, P.K.; Mathews, L.A.; Shiu, A.S.; Maor, M.H.; Woo, S.Y. Stereotactic Radiosurgical Treatment of Cerebral Metastases Arising From Breast Cancer. Am. J. Clin. Oncol. 2007, 30, 310-314. [CrossRef] [PubMed]

32. Kased, N.; Binder, D.K.; McDermott, M.W.; Nakamura, J.L.; Huang, K.; Berger, M.S.; Wara, W.M.; Sneed, P.K. Gamma Knife Radiosurgery for Brain Metastases From Primary Breast Cancer. Int. J. Radiat. Oncol. 2009, 75, 1132-1140. [CrossRef] [PubMed]

33. Kelly, P.J.; Lin, N.U.; Claus, E.B.; Quant, E.C.; Weiss, S.E.; Alexander, B.M. Salvage stereotactic radiosurgery for breast cancer brain metastases. Cancer 2011, 118, 2014-2020. [CrossRef] [PubMed]

34. Huang, Z.; Sun, B.; Shen, G.; Cha, L.; Meng, X.; Wang, J.; Zhou, Z.; Wu, S. Brain metastasis reirradiation in patients with advanced breast cancer. J. Radiat. Res. 2017, 58, 142-148. [CrossRef]

35. Lai, S.; Huang, C.; Wang, C.; Chen, Y.; Lan, K.; Cheng, A.; Kuo, S. Brain Re-irradiation for Breast Cancer Patients With Brain Metastasis After Whole Brain Radiation Therapy: Effect of Epidermal Growth Factor Receptor-2 Status on Clinical Outcome. Int. J. Radiat. Oncol. 2013, 87, S243. [CrossRef]

36. Perez, J.L.; Ozpinar, A.; Kano, H.; Phan, B.; Niranjan, A.; Lunsford, L.D. Salvage Stereotactic Radiosurgery in Breast Cancer Patients with Multiple Brain Metastases. World Neurosurg. 2019, 125, e479-e486. [CrossRef] 
37. Kano, H.; Kondziolka, D.; Zorro, O.; Lobato-Polo, J.; Flickinger, J.; Lunsford, L.D. The results of resection after stereotactic radiosurgery for brain metastases. J. Neurosurg. 2009, 111, 825-831. [CrossRef]

38. Truong, M.T.; Clair, E.G.S.; Donahue, B.R.; Rush, S.C.; Miller, D.C.; Formenti, S.C.; Knopp, E.A.; Han, K.; Golfinos, J.G. Results of Surgical Resection for Progression of Brain Metastases Previously Treatedby Gamma Knife Radiosurgery. Neurosurgery 2006, 59, 86-97. [CrossRef]

39. Mitsuya, K.; Nakasu, Y.; Hayashi, N.; Deguchi, S.; Oishi, T.; Sugino, T.; Yasui, K.; Ogawa, H.; Onoe, T.; Asakura, H.; et al. Retrospective analysis of salvage surgery for local progression of brain metastasis previously treated with stereotactic irradiation: Diagnostic contribution, functional outcome, and prognostic factors. BMC Cancer 2020, 20, 331. [CrossRef]

40. McKay, W.H.; McTyre, E.R.; Okoukoni, C.; Alphonse-Sullivan, N.K.; Ruiz, J.; Munley, M.T.; Qasem, S.; Lo, H.-W.; Xing, F.; Laxton, A.W.; et al. Repeat stereotactic radiosurgery as salvage therapy for locally recurrent brain metastases previously treated with radiosurgery. J. Neurosurg. 2017, 127, 148-156. [CrossRef]

41. Rana, N.; Pendyala, P.; Cleary, R.K.; Luo, G.; Zhao, Z.; Chambless, L.B.; Cmelak, A.J.; Attia, A.; Stavas, M.J. Long-term Outcomes after Salvage Stereotactic Radiosurgery (SRS) following In-Field Failure of Initial SRS for Brain Metastases. Front. Oncol. 2017, 7, 279. [CrossRef]

42. Lucia, F.; Touati, R.; Crainic, N.; Dissaux, G.; Pradier, O.; Bourbonne, V.; Schick, U. Efficacy and Safety of a Second Course of Stereotactic Radiation Therapy for Locally Recurrent Brain Metastases: A Systematic Review. Cancers 2021, 13, 4929. [CrossRef]

43. Scorsetti, M.; Navarria, P.; Ascolese, A.; Clerici, E.; Mancosu, P.; Picozzi, P.; Pecchioli, G.; Franzese, C.; Reggiori, G.; Tomatis, S OS03.4 Gammaknife versus Linac based (EDGE) radiosurgery (SRS) for patients with limited brain metastases (BMS) from different solid tumor: A phase III randomized trial. Neuro-Oncology 2017, 19, iii5-iii6. [CrossRef]

44. Aoki, K.; Nagatani, Y.; Noma, K.; Tsugawa, T.; Kono, N.; Kida, Y.; Harada, N.; Tanoue, Y.; Watanabe, Y. Effective Control of Brain Metastases Irrespective of Distance from Isocenter in Single-isocenter Multitarget Stereotactic Radiosurgery. Anticancer Res. 2021, 41, 2575-2581. [CrossRef]

45. Valenciaga, Y.; Chang, J.; Schulder, M. Evaluating the Use of Combined Gamma Knife/Linac Stereotactic Radiosurgery (SRS) Treatments in Patients with 10 or More Brain Metastases. Int. J. Radiat. Oncol. 2018, 102, e520. [CrossRef]

46. Sebastian, N.T.; Glenn, C.; Hughes, R.; Raval, R.; Chu, J.; DiCostanzo, D.; Bell, E.H.; Grecula, J.; Arnett, A.; Gondal, H.; et al. Linear accelerator-based radiosurgery is associated with lower incidence of radionecrosis compared with gamma knife for treatment of multiple brain metastases. Radiother. Oncol. 2020, 147, 136-143. [CrossRef]

47. Schödel, P.; Jünger, S.T.; Wittersheim, M.; Reinhardt, H.C.; Schmidt, N.; Goldbrunner, R.; Proescholdt, M.; Grau, S. Surgical resection of symptomatic brain metastases improves the clinical status and facilitates further treatment. Cancer Med. 2020, 9, 7503-7510. [CrossRef]

48. Hong, N.; Yoo, H.; Gwak, H.S.; Shin, S.H.; Lee, S.H. Outcome of Surgical Resection of Symptomatic Cerebral Lesions in Non-Small Cell Lung Cancer Patients with Multiple Brain Metastases. Brain Tumor Res. Treat. 2013, 1, 64-70. [CrossRef]

49. Guo, S.; Reddy, C.; Chao, S.; Suh, J. Repeat Whole Brain Irradiation for Patients with Brain Metastases. Int. J. Radiat. Oncol. 2011, 81, S645. [CrossRef]

50. Mittica, G.; Senetta, R.; Richiardi, L.; Rudà, R.; Coda, R.; Castellano, I.; Sapino, A.; Cassoni, P. Meningeal carcinomatosis underdiagnosis and overestimation: Incidence in a large consecutive and unselected population of breast cancer patients BMC Cancer 2015, 15, 1021. [CrossRef]

51. Brower, J.V.; Saha, S.; Rosenberg, S.A.; Hullett, C.R.; Robins, H.I. Management of leptomeningeal metastases: Prognostic factors and associated outcomes. J. Clin. Neurosci. 2016, 27, 130-137. [CrossRef]

52. Gani, C.; Müller, A.-C.; Eckert, F.; Schroeder, C.; Bender, B.; Pantazis, G.; Bamberg, M.; Berger, B. Outcome after whole brain radiotherapy alone in intracranial leptomeningeal carcinomatosis from solid tumors. Strahlenther. Onkol. 2012, 188, 148-153. [CrossRef]

53. Wolf, A.; Donahue, B.; Silverman, J.; Chachoua, A.; Lee, J.K.; Kondziolka, D. Stereotactic radiosurgery for focal leptomeningeal disease in patients with brain metastases. J. Neuro-Oncology 2017, 134, 139-143. [CrossRef]

54. Yamamoto, M.; Serizawa, T.; Shuto, T.; Akabane, A.; Higuchi, Y.; Kawagishi, J.; Yamanaka, K.; Sato, Y.; Jokura, H.; Yomo, S.; et al Stereotactic radiosurgery for patients with multiple brain metastases (JLGK0901): A multi-institutional prospective observational study. Lancet Oncol. 2014, 15, 387-395. [CrossRef]

55. Yamamoto, M.; Kawabe, T.; Sato, Y.; Higuchi, Y.; Nariai, T.; Watanabe, S.; Kasuya, H. Stereotactic radiosurgery for patients with multiple brain metastases: A case-matched study comparing treatment results for patients with 2-9 versus 10 or more tumors. J. Neurosurg. 2014, 121, 16-25. [CrossRef] [PubMed]

56. Haque, W.; Verma, V.; Adeberg, S.; Rustomily, R.; Lo, S.; Butler, E.B.; Teh, B.S. Outcomes following stereotactic radiosurgery or whole brain radiation therapy by molecular subtype of metastatic breast cancer. Rep. Pr. Oncol. Radiother. 2021, 26, 341-351. [CrossRef] [PubMed]

57. Sperduto, P.W.; Mesko, S.; Li, J.; Cagney, D.; Aizer, A.; Lin, N.U.; Nesbit, E.; Kruser, T.J.; Chan, J.; Braunstein, S.; et al. Beyond an Updated Graded Prognostic Assessment (Breast GPA): A Prognostic Index and Trends in Treatment and Survival in Breast Cancer Brain Metastases From 1985 to Today. Int. J. Radiat. Oncol. 2020, 107, 334-343. [CrossRef] [PubMed]

58. Stewart, D.J. A critique of the role of the blood-brain barrier in the chemotherapy of human brain tumors. J. Neuro-Oncology 1994, 20, 121-139. [CrossRef]

59. Rosner, D.; Nemoto, T.; Lane, W.W. Chemotherapy induces regression of brain metastases in breast carcinoma. Cancer 1986, 58, 832-839. [CrossRef] 
60. Boogerd, W.; Dalesio, O.; Bais, E.M.; Van Der Sande, J.J. Response of brain metastases from breast cancer to systemic chemotherapy. Cancer 1992, 69, 972-980. [CrossRef]

61. Zhu, W.; Zhou, L.; Qian, J.-Q.; Qiu, T.-Z.; Shu, Y.-Q.; Liu, P. Temozolomide for treatment of brain metastases: A review of 21 clinical trials. World J. Clin. Oncol. 2014, 5, 19-27. [CrossRef]

62. Christodoulou, C.; Bafaloukos, D.; Linardou, H.; Aravantinos, G.; Bamias, A.; Carina, M.; Klouvas, G.; Skarlos, D. Temozolomide (TMZ) combined with cisplatin (CDDP) in patients with brain metastases from solid tumors: A Hellenic Cooperative Oncology Group (HeCOG) Phase II study. J. Neuro-Oncology 2005, 71, 61-65. [CrossRef]

63. Rivera, E.; Meyers, C.; Groves, M.; Valero, V.; Rn, D.F.; Arun, B.; Ms, K.B.; Yin, G.; Hortobagyi, G.N.; Buchholz, T. Phase I study of capecitabine in combination with temozolomide in the treatment of patients with brain metastases from breast carcinoma. Cancer 2006, 107, 1348-1354. [CrossRef]

64. Berghoff, A.S.; Sax, C.; Klein, M.; Furtner, J.; Dieckmann, K.; Gatterbauer, B.; Widhalm, G.; Rudas, M.; Zielinski, C.C.; Bartsch, R.; et al. Alleviation of brain edema and restoration of functional independence by bevacizumab in brain-metastatic breast cancer: A case report. Breast Care 2014, 9, 134-136. [CrossRef]

65. Berghoff, A.S.; Breckwoldt, M.O.; Riedemann, L.; Karimian-Jazi, K.; Loew, S.; Schlieter, F.; Furtner, J.; Cinci, M.; Thomas, M.; Strowitzki, M.J.; et al. Bevacizumab-based treatment as salvage therapy in patients with recurrent symptomatic brain metastases. Neuro-Oncology Adv. 2020, 2, vdaa038. [CrossRef]

66. Bardia, A.; Hurvitz, S.A.; Tolaney, S.M.; Loirat, D.; Punie, K.; Oliveira, M.; Brufsky, A.; Sardesai, S.D.; Kalinsky, K.; Zelnak, A.B.; et al. Sacituzumab Govitecan in Metastatic Triple-Negative Breast Cancer. New Engl. J. Med. 2021, 384, $1529-1541$. [CrossRef]

67. Brenner, A.; Pandey, R.; Chiou, J.; Floyd, J.; Garcia, M.; Surapaneni, P.; Kaklamani, V.; Lathrop, K.; Crownover, R.; Caron, J.; et al. 373MO Delivery and activity of SN-38 by sacituzumab govitecan in CNS tumours. Ann. Oncol. 2020, 31, S401. [CrossRef]

68. Anders, C.; Deal, A.M.; Abramson, V.; Liu, M.C.; Storniolo, A.M.; Carpenter, J.T.; Puhalla, S.; Nanda, R.; Melhem-Bertrandt, A.; Lin, N.U.; et al. TBCRC 018: Phase II study of iniparib in combination with irinotecan to treat progressive triple negative breast cancer brain metastases. Breast Cancer Res. Treat. 2014, 146, 557-566. [CrossRef]

69. Zhang, T.; Lip, H.; He, C.; Cai, P.; Wang, Z.; Henderson, J.T.; Rauth, A.M.; Wu, X.Y. Multitargeted Nanoparticles Deliver Synergistic Drugs across the Blood-Brain Barrier to Brain Metastases of Triple Negative Breast Cancer Cells and Tumor-Associated Macrophages. Adv. Health Mater. 2019, 8, 1900543. [CrossRef]

70. Lin, N.U.; Borges, V.; Anders, C.; Murthy, R.K.; Paplomata, E.; Hamilton, E.; Hurvitz, S.; Loi, S.; Okines, A.; Abramson, V.; et al Intracranial Efficacy and Survival With Tucatinib Plus Trastuzumab and Capecitabine for Previously Treated HER2-Positive Breast Cancer With Brain Metastases in the HER2CLIMB Trial. J. Clin. Oncol. 2020, 38, 2610-2619. [CrossRef]

71. Lin, N.U.; Diéras, V.; Paul, D.; Lossignol, D.; Christodoulou, C.; Stemmler, H.-J.; Roché, H.; Liu, C.M.H.; Greil, R.; Ciruelos, E.; et al Multicenter Phase II Study of Lapatinib in Patients with Brain Metastases from HER2-Positive Breast Cancer. Clin. Cancer Res. 2009, 15, 1452-1459. [CrossRef] [PubMed]

72. Morikawa, A.; De Stanchina, E.; Pentsova, E.; Kemeny, M.M.; Li, B.T.; Tang, K.; Patil, S.; Fleisher, M.; Van Poznak, C.; Norton, L.; et al. Phase I Study of Intermittent High-Dose Lapatinib Alternating with Capecitabine for HER2-Positive Breast Cancer Patients with Central Nervous System Metastases. Clin. Cancer Res. 2019, 25, 3784-3792. [CrossRef] [PubMed]

73. Freedman, R.A.; Gelman, R.S.; Anders, C.K.; Melisko, M.E.; Parsons, H.A.; Cropp, A.M.; Silvestri, K.; Cotter, C.M.; Componeschi, K.P.; Marte, J.M.; et al. TBCRC 022: A Phase II Trial of Neratinib and Capecitabine for Patients With Human Epidermal Growth Factor Receptor 2-Positive Breast Cancer and Brain Metastases. J. Clin. Oncol. 2019, 37, 1081-1089. [CrossRef] [PubMed]

74. Montemurro, F.; Delaloge, S.; Barrios, C.; Wuerstlein, R.; Anton, A.; Brain, E.; Hatschek, T.; Kelly, C.M.; Peña-Murillo, C.; Yilmaz, M.; et al. Trastuzumab emtansine (T-DM1) in patients with HER2-positive metastatic breast cancer and brain metastases: Exploratory final analysis of cohort 1 from KAMILLA, a single-arm phase IIIb clinical trial 放. Ann. Oncol. 2020, 31, 1350-1358. [CrossRef]

75. The Oncologist. Available online: https://theoncologist.onlinelibrary.wiley.com/page/journal/1549490x/homepage/ conference_perspectives/sabc2021/destiny (accessed on 30 January 2022).

76. Lin, N.U.; Pegram, M.; Sahebjam, S.; Ibrahim, N.; Fung, A.; Cheng, A.; Nicholas, A.; Kirschbrown, W.; Kumthekar, P. Pertuzumab Plus High-Dose Trastuzumab in Patients With Progressive Brain Metastases and HER2-Positive Metastatic Breast Cancer: Primary Analysis of a Phase II Study. J. Clin. Oncol. 2021, 39, 2667-2675. [CrossRef]

77. Stewart, D.J.; Dahrouge, S. Response of brain metastases from breast cancer to megestrol acetate: A case report. J. Neuro-Oncology 1995, 24, 299-301. [CrossRef]

78. Salvati, M.; Cervoni, L.; Innocenzi, G.; Bardella, L. Prolonged Stabilization of Multiple and Single Brain Metastases from Breast Cancer with Tamoxifen. Report of Three Cases. Tumori J. 1993, 79, 359-362. [CrossRef]

79. Madhup, R.; Kirti, S.; Bhatt, M.; Srivastava, P.; Srivastava, M.; Kumar, S. Letrozole for brain and scalp metastases from breast cancer-A case report. Breast 2006, 15, 439-441. [CrossRef]

80. Brastianos, P.K.; Kim, A.E.; Wang, N.; Lee, E.Q.; Ligibel, J.; Cohen, J.V.; Chukwueke, U.N.; Mahar, M.; Oh, K.; White, M.D.; et al Palbociclib demonstrates intracranial activity in progressive brain metastases harboring cyclin-dependent kinase pathway alterations. Nat. Cancer 2021, 2, 498-502. [CrossRef] 
81. Tolaney, S.M.; Sahebjam, S.; Le Rhun, E.; Bachelot, T.; Kabos, P.; Awada, A.; Yardley, D.; Chan, A.; Conte, P.; Diéras, V.; et al. A Phase II Study of Abemaciclib in Patients with Brain Metastases Secondary to Hormone Receptor-Positive Breast Cancer. Clin. Cancer Res. 2020, 26, 5310-5319. [CrossRef]

82. Soffietti, R.; Abacioglu, U.; Baumert, B.; Combs, S.E.; Kinhult, S.; Kros, J.M.; Marosi, C.; Metellus, P.; Radbruch, A.; Freixa, S.S.V.; et al. Diagnosis and treatment of brain metastases from solid tumors: Guidelines from the European Association of Neuro-Oncology (EANO). Neuro-Oncology 2017, 19, 162-174. [CrossRef]

83. Fontanella, C.; De Carlo, E.; Cinausero, M.; Pelizzari, G.; Venuti, I.; Puglisi, F. Central nervous system involvement in breast cancer patients: Is the therapeutic landscape changing too slowly? Cancer Treat. Rev. 2016, 46, 80-88. [CrossRef]

84. Palmer, J.D.; Trifiletti, D.M.; Gondi, V.; Chan, M.; Minniti, G.; Rusthoven, C.G.; E Schild, S.; Mishra, M.V.; Bovi, J.; Williams, N.; et al. Multidisciplinary patient-centered management of brain metastases and future directions. Neuro-Oncology Adv. 2020, 2, vdaa034. [CrossRef] 